\title{
Successful Management of Khat Chewing-induced Gingival Recession by Using Tunnel Technique Utilizing Subepithelial Connective Tissue Graft: A Case Report
}

\author{
Mohammed S Al-Akhali
}

\begin{abstract}
Aim: Treatment of an unusual gingival recession induced by khat chewing habit.

Background: Gingival recession induced by khat chewing was confirmed by many authors. However, there is no proposal for treatment of gingival recession induced by chewing khat.

Case description: A systemically healthy nonsmoking male khat chewer aged 38 years presented with class III gingival recession around the lower right incisor. The treatment approach involved a subepithelial connective tissue graft with a tunnel procedure.

Conclusion: A full coverage of khat-induced recession was achieved by using tunnel technique utilizing subepithelial connective tissue graft at 1-year follow-up.

Clinical significance: Treatment of gingival recession, including those induced by mechanical trauma such as chewing habits is considered as an esthetic demand and it is the responsibility of the clinician to determine the proper treatment plan for the correcting esthetic and functional defects of the periodontal tissues.

Keywords: Gingival recession, Khat chewing, Periodontics.

The Journal of Contemporary Dental Practice (2019): 10.5005/jp-journals-10024-2659
\end{abstract}

\section{BACKGROUND}

Marginal tissue recession is frequently associated with esthetic fears, root hypersensitivity, and anxiety of tooth loss. Numerous etiological factors that may lead to gingival recession are improper teeth brushing, mal position tooth, periodontal disease, strong attachment of frenum, trauma from occlusion, subgingival overhangs of restorations, extractions of adjacent teeth, orthodontic movement, iatrogenic factors, and bone dehiscence. ${ }^{1}$ Habit is an essential cause in the initiation and progression of periodontal destruction. Frequently, the presence of unsuspected habit is revealed in patients who have failed to respond to periodontal therapy. ${ }^{2}$

Khat is a common name for Catha edulis Forsk; it belongs to the botanical family Celastraceae, a tree that is found in Yemen and other countries, especially those located at or near the African horn. The fresh leaves of the plant have been chewed since ancient times due to their stimulating properties. ${ }^{3}$ Most of the studies have examined the effect of khat chewing on periodontium confirmed the ability of khat chewing to induce gingival recession among khat chewers. ${ }^{4-9}$ Gingival recession was treated by using different techniques. Miller ${ }^{10}$ categorized marginal gingival tissue recession into four types. Poor prognosis with partial coverage can be anticipated for treatment of class III gingival recession. ${ }^{10}$ Langer and Langer ${ }^{11}$ were the first who defined the indications and protocols necessary for achieving success in treatment procedures of using subconnective tissue graft for treatment of gingival recessions. The utilization of connective tissue graft ${ }^{12,13}$ was examined in different ways, below a lateral or a coronal repositioned flap, below a flap positioned to its initial position, below a double papilla flap, or utilizing a tunnel procedure covered by undetached interdental papilla. ${ }^{14}$ To our knowledge, no single research has managed khat
Division of Periodontology, Faculty of Dentistry, Jazan University, Kingdom of Saudi Arabia; Department of Periodontology, Faculty of Dentistry, Sana'a University, Yemen

Corresponding Author: Mohammed S Al-Akhali, Division of Periodontology, Faculty of Dentistry, Jazan University, Kingdom of Saudi Arabia; Department of Periodontology, Faculty of Dentistry, Sana'a University, Yemen, Phone: +966569836675 , e-mail: sultanperiodontics@gmail.com

How to cite this article: Al-Akhali MS, Successful Management of Khat Chewing-induced Gingival Recession by Using Tunnel Technique Utilizing Subepithelial Connective Tissue Graft: A Case Report. J Contemp Dent Pract 2019;20(10):1235-1238.

Source of support: Nil

Conflict of interest: None

chewing-induced gingival recession. This study introduces clinically successful root coverage of Miller's class III khat chewing-induced gingival recession using tunnel subepithelial connective tissue graft procedure which considers quick healing and less invasive periodontal surgical procedure. ${ }^{14}$

\section{Case Description}

A systemically healthy nonsmoking male khat chewer aged 38 years presented to the clinic of periodontology in the Faculty of Dentistry, Jazan University, with a chief complaint of receding gingiva and root hypersensitivity on his right mandibular incisor (Fig. 1A) with no abrasive oral habits. No trauma from occlusion was observed. His oral hygiene was good. He did not take any medications. Upon questioning the patient, he admitted that 
he has the habit of chewing khat about 7 hours per day for more than 10 years and that the bolus of khat leaves move from buccal vestibule to anterior segment of his teeth and caused gingival recession. The lower right incisor had grade I mobility and recession of $4 \mathrm{~mm}$ on labial surface. The recession was extended beyond mucogingival junction (MGJ) with associated interdental hard and soft tissue loss (Fig. 1A), so it was diagnosed as Miller's class III gingival recession. This recession was noticed by the patient for 3 years and had no history of surgical interventions. As an initial therapy scaling, root planning and polishing were done. Oral hygiene was reinforced, and the patient was asked to refrain from khat chewing. After completion of phase I therapy, the patient was recalled regularly for maintenance therapy for a period of 4 weeks. Reporting this case was approved by the research committee of the faculty of dentistry, Jazan University. Additionally, informed consent from the patient has been obtained. The connective tissue graft with tunnel technique was selected to treat gingival recession class III on the lower right incisor.

A local anesthetic was infiltrated around lower right incisor; a sulcular incision was designed around lower right incisor using blade \#15 by sharp dissection leaving the papillae tips undetached below the proximal contact point, and then underlining using periosteal elevator was done, to detach the gingiva and periosteum deeply from the mucogingival junction (Fig. 1B). Two vertical incisions were made apical to the interproximal papillae which was still attached around the lower right incisor (Fig. 1B). The extension of two vertical incisions apically beyond the mucogingival junction increases the gingival mobility, which facilitates connective tissue coverage particularly from coronal side. It was further planned to smooth and remove any remaining granulation tissue, toxins, and other irregularities. No chemical root modifiers were used. Sickle scaler was used to induce bleeding and to remove any necrotic cementum. Right palatal area was the donor site. After performing profound local anesthesia, a first horizontal line of incision was placed $4 \mathrm{~mm}$ from the gingival margin in such a way that blade \#15 undermines a partial thickness flap from the supraconnective tissue that we wanted to harvest. This was thin enough that sufficient connective tissue (1.5-2 $\mathrm{mm}$ ) could be harvested below it and was thick enough that the blade is not visible through the epithelium over it (Fig. 1C). The incision extended forward from the first molar to the first premolar region horizontally and carried to the depth slightly short of the junction of the horizontal and vertical walls of the palate. The second incision was carried out parallel to the first incision but deeper and from the subconnective tissue keeping the blade very close to the periosteum. It was also carried apically to the same depth as the first incision. The graft was then harvested by using $4-0$ suture, after releasing from the mesial, distal, and apical ends in the envelope fashion, and stored in cold saline moistened gauze (Fig. 1C), and the donor site was sutured. The bleeding stopped within a few minutes. Acrylic stent was not delivered as the wound was completely closed. The connective tissue graft was delicately inserted inside the pouch around lower right incisor using 4-0 sutures and was then stabilized with the flap (Fig. 1D). The graft was positioned and adapted firmly to the recipient site. The graft was sutured around the incisor to secure it in position. Finally, the gingiva was sutured from both sides over the connective tissue using silk 4-0 sutures (Fig. 1E). A periodontal pack was not used to avoid pressure on the graft and flap. The patient was informed to stop brushing of his teeth for 72 hours around the surgical area and asked to avoid touching the surgical area. The patient was called after 24 hours, 3 days, 1 week, 10 days (sutures removed), and 2 weeks. Surgical area healed without any of sloughing after 1 month of follow-up, the healing progressed, and the gingival recession was totally covered with an excellent cosmetic outcome (Fig. 1F). The patient was informed to return every 3 months for periodic follow-up.

\section{Discussion}

Khat is considered as a causative factor for gingival recession, ${ }^{4-9}$ and it is related to mechanical pressure of the khat leaves on the gingival tissue. The leaves of khat are stored inside the mouth vestibule between the gingiva and the cheeks for at least 4 hours up to more than 8 hours a day. Almost, the chewing habit is practiced for many years. The pressure from khat bolus directed to affect several teeth in one side or more than one side of the mouth resulting in gingival recession on the posterior teeth and sometimes on the anterior teeth as well. ${ }^{8}$

The patient was strongly prohibited from chewing khat as a part of treatment plan to avoid the recurrence of gingival recession. The extension of two vertical incisions apically beyond the mucogingival junction increases the gingival mobility which facilitates connective tissue coverage particularly from coronal side. This feature is important for lower anterior teeth where the facial gingiva and alveolar mucosa are more movable than the gingival tissue around the upper teeth which is detachable from the maxilla. So it was necessary to utilize this feature in the lower jaw to get more root coverage by using tunnel connective tissue graft technique. It was easier to harvest the connective tissue graft from the left palatal site because the left palatal site is more visible and accessible to the surgeon as the gingival recession is located on the right side, which makes the position of surgeon more accessible to the left side. However, in this case, the right palatal site was selected to harvest the connective tissue because the left palatal side around the 1st molar has gingival recession which limited the harvest of the connective tissue from the left palatal side of the maxilla. According to the Miller classification, ${ }^{10}$ Class I and II types of defects in which the interdental bone support is intact have the best potential for complete root coverage, while only partial root coverage is thought to be achievable in Miller class III and IV type defects. These defects are associated with loss of interdental bone or malposition, and only partial root coverage is achievable. However, complete root coverage is attained in some class III recessions. ${ }^{15}$

Prognosis of treatment of class III gingival recession is poor, and only partial coverage can be expected and the impact of interproximal bone loss on root coverage was still weak. It was found that the tunnel subconnective tissue graft procedure to be a sustainable alternative with least trauma to the patient for treatment of class III gingival recession around lower central incisor. The period of follow-up in this study was not enough because of the patient traveling outside of country and loss of contact with him. It seems that the treatment of gingival recession induced by habits after elimination of causative habit has a more favorable response to treatment by surgical coverage than gingival recessions induced by periodontal disease. However, clinical control studies should be done utilizing this technique and other root coverage surgical techniques targeting different teeth affected by gingival recession induced by khat chewing compared to gingival recession induced by periodontal disease with large sample sizes and long period of follow-up to determine the prognosis of root coverage procedures in the treatment of gingival recession induced by khat chewing. 

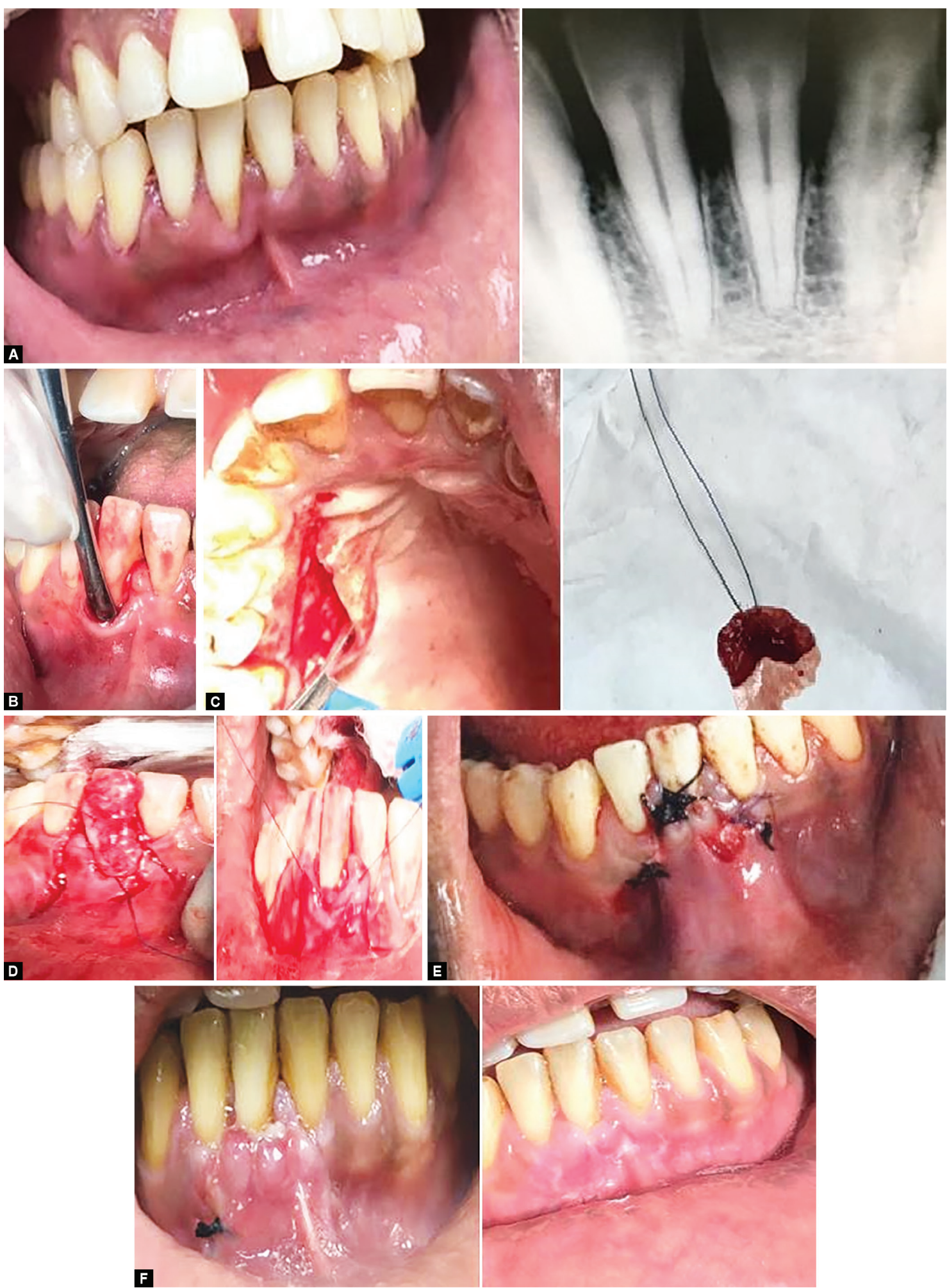

Figs $1 \mathrm{~A}$ to F: (A) Preoperative, clinical, and preapical radiograph showing class III gingival recession on lower anterior central with $4 \mathrm{~mm}$ of depth; (B) A full-thickness flap was raised by using periosteal elevator till the mucogingival junction, and beyond that, a partial thickness flap was raised in the alveolar mucosa; (C) The blade was placed approximately parallel to the long axis of the palate just $4 \mathrm{~mm}$ apical to the gingival margin to make the first incision, and the subepithelial connective tissue graft was harvested; (D) The connective tissue graft was transfer to the recipient site and delicately inserted inside the pouch around lower right incisor using 4-0 sutures; the graft was stabilized with the flap; (E) The flap was sutured from both sides over the connective tissue graft used silk 4-0 sutures; the tip of the interproximal papillae on coronal sides is still attached to the bone below the proximal contact point without suturing; (F) Follow-up of the case after 2 days and one month of surgery: the healing progressed uneventfully, and the gingival recession was totally covered with an excellent esthetic result 


\section{Conclusion}

Complete coverage of khat chewing-induced gingival recession was achieved utilizing a tunnel connective tissue graft technique with 1-month follow-up.

\section{Clinical Significance}

Over the years, dentistry is evolving, so dentists are not only required to treat disease but also to manage with the esthetic demands of the patients. Modern dentistry has focused on cosmetic dental therapy including the treatment of gingival deformities, which cannot be treated without surgical treatments. Treatment of gingival recession, including those induced by mechanical trauma such as chewing habits, is considered as an esthetic demand, and it is the responsibility of the clinician to determine the proper treatment plan for correcting the esthetic and functional defects of the periodontal tissues.

\section{ACKNOWLedgment}

Thanks to Dr Esam Halboub for the final revision of this article before publication.

\section{References}

1. Juliana A. Subepithelial connective tissue graft: a case report. Rev Sul-bras Odontol 2011;8:357-362.

2. Kornman KS. Diagnostic and Prognostic Tests for Oral Diseases: Practical Applications. J Dent Educ 2005;69:498-508.

3. Halbach H. Medical aspects of the chewing of qat leave. Bull WHO 1972;47:21-29.

4. Al-Akhali MS, Al-Moraissi EA. Khat chewing habit produces a significant adverse effect on the periodontal, oral health: a systematic review and meta analysis. J Periodontal Res 2017;00:1-9. DOI: 10.1111/ jre.12468.

5. Al-Alimi A, Halboub $E$, et al. Independent determinants of periodontitis in Yemeni adults: a case-control study. Int J Dent Hyg 2018 Jul 2. DOI: $10.1111 /$ idh.12352.

6. AL-Maweri SA, AIAkhali M. Oral hygiene and periodontal health status among khat chewers. A case-control study. J Clin Exp Dent 2017;9(5):e629-e634. DOI: 10.4317/jced.53520.

7. Yarom N, Epstein J, et al. Oral manifestations of habitual khat chewing: a case-control study. Oral Surg Oral Med Oral Pathol Oral Radiol Endod 2010;109:e60-e66. DOI: 10.1016/j.tripleo.2010.02.022.

8. Al-Akhali M, Al-Haddad KA, et al. Tooth lost and gingival recession as a risk factor of khat chewing in Yemen. Cairo Dent J 2008;2:171-176.

9. Rosenzweig K, Smith P. Periodontal health in various ethnic groups. J Periodontal Res 1966;1:250-259. DOI: 10.1111/j.1600-0765.1966. tb01869.x.

10. Miller PD Jr. A classification of marginal tissue recession. Int $J$ Periodontics Restorative Dent 1985;5:8-13.

11. Langer B, Langer L. Subepithelial connective tissue graft technique for root coverage. J Periodontol 1985;56:715-720. DOI: 10.1902/ jop.1985.56.12.715.

12. Caffesse RG, Espinel MC. Lateral sliding flap with a free gingival graft technique in the treatment of localized gingival recessions. Int J Periodont Rest Dent 1981;1:22-29.

13. Harris RJ. A comparison of 2 root coverage techniques: Guided tissue regeneration with a bioabsorbable matrix style membrane versus a connective tissue graft combined with a coronally positioned pedicle graft without vertical incisions: Results of a series of consecutive cases. J Periodontol 1998;69:1426-1434. DOI: 10.1902/ jop.1998.69.12.1426.

14. Zabalegui I, Sicilia A, et al. Treatment of multiple adjacent gingival recessions with the tunnel subepithelial connective tissue graft: a clinical report. Int J Period Rest Dent 1999;19:199-206.

15. Esteibar JR, Zorzano LA, et al. Complete root coverage of Miller Class III recessions. Int J Periodontics Restorative Dent 2011;31(4):e1-e7. 